\title{
Preparation and Modification of PU Membrane and Its Swelling and Pervaporation Properties
}

\author{
Hong Ye* \\ Beijing Engineering and Technology Research Center of Food Additives \\ Beijing Technology \& Business University (BTBU) \\ Beijing 100048, China \\ Beijing Higher Institution Engineering Research Center of Food Additives and Ingredients \\ Beijing Technology \& Business University (BTBU) \\ Beijing 100048, China \\ *Corresponding author
}

Jian $\mathrm{Yu}$

Beijing Engineering and Technology Research Center of

Food Additives

Beijing Technology \& Business University (BTBU)

Beijing 100048, China

\section{Boyu Song}

Environmental Protection Research Institute of Light Industry Beijing Academy of Science and Technology

Beijing 100089, China

\author{
Zhongguo Zhang \\ Environmental Protection Research Institute of Light Industry \\ Beijing Academy of Science and Technology \\ Beijing 100089, China \\ Yiping Liao \\ Beijing Engineering and Technology Research Center of \\ Food Additives \\ Beijing Technology \& Business University (BTBU) \\ Beijing 100048, China
}

\begin{abstract}
PU(Polyurethane) material is promising in pervaporation application. Polyether-based PU prepolymers were used to prepare a series of PU membranes. Then, the structure and properties of the above-prepared membrane materials were characterized by means of FTIR and swelling experiment. And the performance of pervaporation separation of phenol/water was studied. The result shows that The swelling degree is decreased by the addition of zeolite. Using solution with phenol $(0.5 \mathrm{wt} \%)$ in water. With feed temperature increased, there's an anti-trade-off phenomenon. At $80{ }^{\circ} \mathrm{C}$, the flux is $319.95 \mathrm{~kg} \cdot \mu \mathrm{m} \cdot \mathrm{m}-2 \cdot \mathrm{h}-1$, and separation factor is 7.19 .
\end{abstract}

Keywords-polyurethane; membrane material; pervaporation

\section{INTRODUCTION}

Polyurethane (PU) receives increasing concern for its good membrane-forming and tolerability. The soft segment of PU usually has good permeability and adsorption properties for organics, while the hard segment phase can form a rigid physical crosslinking relying on hydrogen bonds ${ }^{[1]}$. It can ensure the stable operation of the separation process and has great potential and significance in industrial technology and academic fields.

Gutpa $^{[2-3]}$ used PU membranes to separate phenol from water. As a result, the high separation factor over 1000 was obtained, but the total flux was very limited (less than $10 \mathrm{~g} / \mathrm{m}^{2} \mathrm{~h}$ ). Das ${ }^{[4]}$ intended to prepare porous structure of $\mathrm{PU}$. $\mathrm{LiCl}$ was used as pore-forming agent. The porous PU membrane had $44.3 \%$ higher flux than PU with totally dense structure. But in general, the flux of these membranes was less than $80 \mathrm{~g} / \mathrm{m}^{2} \mathrm{~h}$. So more modification work of PU should be developed.

In this study, polyether-based PU prepolymers were used to prepare a series of PU membranes. Then, the structure and properties of the above-prepared membrane materials were characterized by means of FTIR and swelling experiment. And the performance of pervaporation separation of phenol/water was studied.

\section{EXPERIMENT}

\section{A. Materials}

NCO-terminated PU prepolymer (polyether based, NCO-PRE,) and 4,4'-Methylene bis(2-chloroaniline) (MOCA) was supplied by Dongguan rubber products co. LTD. NCO-PRE was used as received with the hardness of SHOREA78 and SHOREA85. MOCA was dried under vacuum before using. N,N'-dimethyl acetylamide (DMAc) was purchased from huihaikeyi Co. Ltd. MDA and purified by distillation under reduced pressure over calcium hydride and

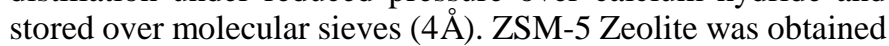
from Catalyst plant of Nankai University with ratio of $\mathrm{Si} / \mathrm{Al} 260$ and dried under vacuum before using. 


\section{B. Preparation and Characterization of Different $P U$ Membrane}

PU material was synthesized as shown by Figure 1. The NCO-PRE was degassed at $80^{\circ} \mathrm{C}$ under vacuum. Then the solution of MOCA and DMAc was put into NCO-PRE with stirring. For the zeolite-modified membrane, the ZSM-5 (about $1 \%-10 \%$ ) was also add. After 5 minutes, the solution was degassed at room temperature. The above solution was cast on a Teflon ${ }^{\circledR}$ plate and left under room temperature for 30 minutes followed by thermal curing at $80^{\circ} \mathrm{C}$ for $10 \mathrm{~h}$ to remove the residual solvent. The thickness of these PU membranes was 80-130 $\mu \mathrm{m}$.

\section{Characterization of Membranes}

FTIR measurement (Nicolet IR560) was used to characterize the chemical structures of PU membranes. The samples for that were obtained by spreading a thin film of their solutions in DMAc.

The dried PU membranes were weighed and then immersed into aqueous solution of $1-5 \mathrm{wt} \%$ phenol in sealed vessels at $30^{\circ} \mathrm{C}$ for $48 \mathrm{~h}$. The membranes were carefully wiped by tissue papers to remove surface solvent, and then weighted to measure the weight of the swollen membrane obtained. The degree of swelling (DS) of the membranes was then determined from following equation:

$$
D S=\frac{m-m_{0}}{m_{0}} \times 100 \%
$$

Where $m_{0}$ and $m$ were the weights of dry and swollen membranes respectively.

The thicknesses of the membranes were determined by using a micro screw gauge.

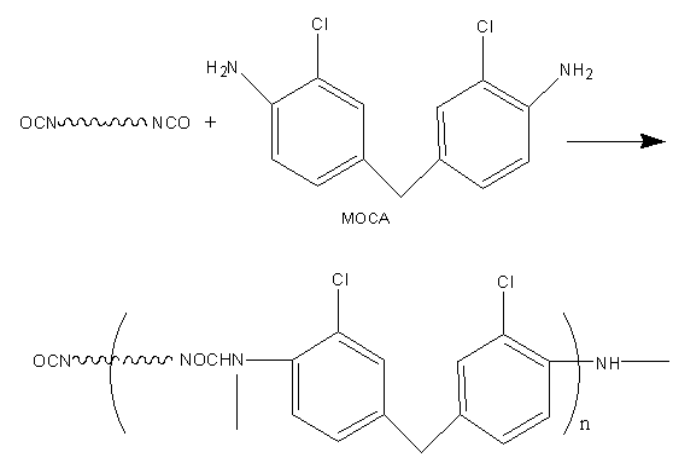

FIGURE I. REACTION FLOW CHART OF PU MEMBRANE

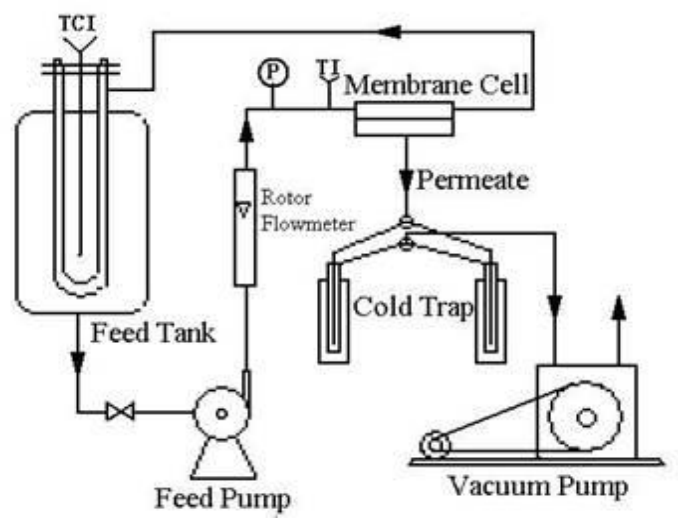

FIGURE II. PERVAPORATION PERFORMANCES TEST APPARATUS

\section{Pervaporation Experiments}

The pervaporation performances of the membranes were tested by using an apparatus developed in our laboratory as shown in Figure 2. The feed was heated and circulated from the feed tank (volume of $1.5 \times 10^{-3} \mathrm{~m}^{3}$ ) through the upstream side of the membrane cell by a pump with adjustable function of flow rate. A membrane supported by a porous sintered stainless steel in the permeate side was mounted in the pervaporation cell. The measurements were carried out for phenol/water mixtures in which the content of phenol was $0.5 \mathrm{wt} \%$. The feed mixture was maintained at temperature between $60^{\circ} \mathrm{C}$ and $80^{\circ} \mathrm{C}$ using a thermostat. The effective area of the membrane was $2.2 \times 10^{-3} \mathrm{~m}^{2}$. Vacuum on the permeate side was maintained below $700 \mathrm{~Pa}$. Two cold traps were set in parallel allowing the collection of permeate without rupture of the vacuum. The concentrations of permeate and feed mixture were analyzed by gas chromatography. The permeability was evaluated by the normalized flux $\left(\mathrm{J}, \mathrm{kg} \cdot \mu \mathrm{m} \cdot \mathrm{m}^{-2} \cdot \mathrm{h}^{-1}\right)$ as defined in formula (2) to compare pervaporation performances of membranes with different thickness.

$$
J=\frac{Q}{A \cdot T} \cdot l
$$

Where $\mathrm{Q}(\mathrm{kg})$ is the total mass of permeate collected through the effective area of membrane (A, m2) during time $\mathrm{T}(\mathrm{h}), 1$ is membrane thickness ( $\mu \mathrm{m})$.

The selectivity of membrane was demonstrated by separation factor and defined as

$$
\alpha=\frac{Y_{A} \cdot X_{B}}{X_{A} \cdot Y_{B}}
$$

Where YA and YB represent the weight fractions of phenol and water in the downstream permeate, and $\mathrm{XA}$ and $\mathrm{XB}$ represent those in the feed mixture, respectively. 


\section{RESULT ANG DISCUSSION}

\section{A. Synthesis and Preparation of PU Membranes}

As shown by Table 1, a series of PU and modified PU were prepared with different ratio of NCO-PRE, MOCA, DMAc and Zeolite. 1\# membrane shows good membrane forming properties and can be tested by PV experiment. And swelling properties of membrane $1 \#, 4 \#, 5 \#$ and $6 \#$ were investigated because they cannot be used for separation. 2\# material was prepared with prepolymer of $85 \mathrm{~A}$, and fast gelation happened during the reaction. As a result, the membrane is not prepared. There are higher content zeolites in 5\# and 6\# membranes than 4\#. Although more solvent of DMAc was used in 5\# and 6\#, but the zeolites were badly dispersed in membrane solution and showed an aggregation.

TABLE I. PREPARATION OF PU MEMBRANES WITH DIFFERENT COMPOSITON OF FEED STOCK

\begin{tabular}{ccccccc}
\hline Number & Compositon & $\begin{array}{c}\text { NCO-PRE:MOCA } \\
\text { (weight ratio) }\end{array}$ & $\begin{array}{c}\text { NCO-PRE:DMAc } \\
\text { (weight ratio) }\end{array}$ & Zeolite/ NCO-PRE & $\begin{array}{c}\text { Preparation thickness } \\
\text { (counted by lays of plastic) }\end{array}$ & Membrane perparation \\
\hline $1 \#$ & 78 A+MOCA & $100: 10.6$ & $13: 1$ & 0 & 4 & Afford PV test \\
$2 \#$ & 85 A+MOCA & $100: 12.8$ & $10: 1$ & 0 & 2 & Gelation, no membrane forming \\
$3 \#$ & 78 A+MOCA & $100: 10.6$ & $10: 1$ & 0 & $1 \%$ & Good membrane forming \\
$4 \#$ & 78 A+MOCA & $100: 10.6$ & $13: 1$ & $5 \%$ & 2 & Good membrane forming \\
$5 \#$ & 78 A+MOCA & $100: 10.6$ & $10: 1$ & $10 \%$ & 2 & With zeolite dispersed unevenly \\
$6 \#$ & 78 A+MOCA & $100: 10.6$ & $5: 1$ & & Very bad dispersion of zeolite \\
\hline
\end{tabular}

\section{B. FTIR Characterization of PU Membranes}

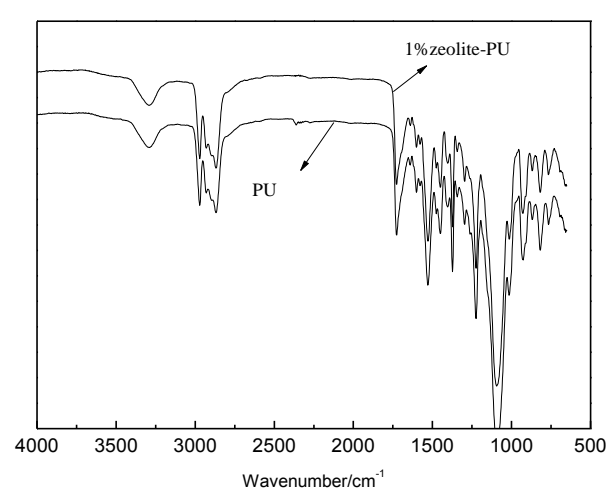

FIGURE III. FTIR SEPCTRUM OF PU AND ZEOLITE-MODIFIED PU MEMBRANES

Figure 3 was the FTIR sepctrum of PU and zeolite-modified PU membranes. As shown by FTIR, the PU membranes thus obtained shows the characteristic peaks of urethane groups: $1720 \mathrm{~cm}^{-1}$ related to stretching of $\mathrm{C}=\mathrm{O}$ group, $1540 \mathrm{~cm}^{-1}$ related to bending vibration of N-H group, obvious bands from 2800 $\mathrm{cm}^{-1}$ to $3000 \mathrm{~cm}^{-1}$ related to $\mathrm{C}-\mathrm{H}$ stretching vibration.

The peak at $2270 \mathrm{~cm}^{-1}$ attributed to -NCO group from TDI cannot be observed in FTIR spectra. That means - NCO has been reacted totally.

Besides, the PU and zeolite-modified PU membranes do not show great difference. That can be due to small amount of zeolite $(1 \%)$.
C. Effect of Zeolite on Swelling Properties of PU Membranes

Table 2 shows the effect of zeolite on swelling properties of PU. Obviously, the addition of zeolite decreases the swelling degree greatly from $45.16 \%$ to $28.57 \%$ with zeolite content from $1 \%$ to $10 \%$. Zelite will block the movement of polymer chain, and limit the rotation and arrangement of segments. So the modified PU becomes less flexiable and free volume than pure PU membrane. As a result, the swelling degree is decreased by the addition of zeolite.

TABLE II. EFFECT OF CONTENT OF ZEOLITE ON SWELLING PROPERTIES OF PU

\begin{tabular}{cccc}
\hline membrane & Shore hardness/A & NCO-PRE:DMAc & Swelling degree/\% \\
\hline PU & 78 & $13: 1$ & 45.16 \\
$1 \%$ zeolite -PU & 78 & $13: 1$ & 34.48 \\
$5 \%$ zeolite -PU & 78 & $10: 1$ & 31.26 \\
$10 \%$ zeolite -PU & 78 & $5: 1$ & 28.57 \\
\hline
\end{tabular}

\section{Effect of Temperature on Pervaporation Properties of PU} Membranes

Figure 4 shows the separation performance of 1 \# membrane using solution with phenol $(0.5 \mathrm{wt} \%)$ in water. With feed temperature increasing from 40 to $80{ }^{\circ} \mathrm{C}$, both flux and separation factor increase. That's an anti-trade-off phenomenon. At $80{ }^{\circ} \mathrm{C}$, the flux is $319.95 \mathrm{~kg} \cdot \mu \mathrm{m} \cdot \mathrm{m}^{-2} \cdot \mathrm{h}^{-1}$, and separation factor is 7.19. Increasing temperature accelerates the process of solution and diffusion. The driving force across the membrane also increase, which is beneficial for small molecules to pass through the membrane. On the other side, the free volume of polymer will be improved by increased temperature and provide more space to diffuse. As a result, the total flux increases. Relatively speaking, the flux of phenol is more sensitive to 
temperature and shows more increase than water, so the separation factor is also increased with temperature.

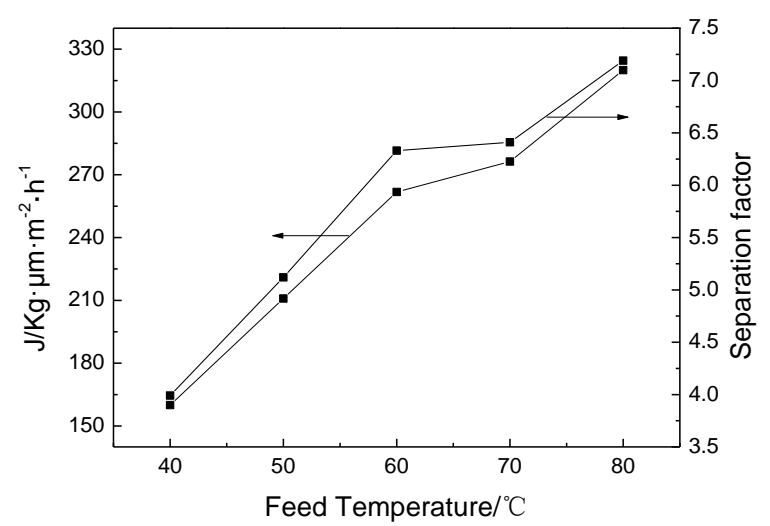

FIGURE IV. EFFECTS OF FEED TEMPERATURE ON PERVAPORATION PERFORMANCES OF PU MEMBRANE

\section{SUMMARY}

Polyurethane is the best candidate material for pervaporation application. The swelling degree is decreased by the addition of zeolite. Using solution with phenol $(0.5 \mathrm{wt} \%)$ in water. With feed temperature increased, there's an anti-trade-off phenomenon. At $80{ }^{\circ} \mathrm{C}$, the flux is $319.95 \mathrm{~kg} \cdot \mu \mathrm{m} \cdot \mathrm{m}^{-2} \cdot \mathrm{h}^{-1}$, and separation factor is 7.19 .

\section{ACKNOWLEDGEMENT}

This research was financially supported by the National Science Foundation (No. 20906001), Beijing Natural Science Foundation (L140009), The Importation and Development of High-Caliber Talents Project of Beijing Municipal Institutions (CIT\&TCD201404032).

\section{REFERENCES}

[1] Zhu Q, Chu Y, Wang Z, et al. Robust superhydrophobic polyurethane sponge as a highly reusable oil-absorption material. Journal of Materials Chemistry A, 1 (2013): 5386-5393.

[2] Gupta T, Pradhan N C, Adhikari A. Separation of phenol from aqueous solution by pervaporation using HTPB-based polyurethaneurea membrane. Journal of Membrane Science, 217(2003) 43-53.

[3] Gupta T, Pradhan N C, Adhikari B. Synthesis and performance of a novel polyurethaneurea as pervaporation membrane for the selective removal of phenol from industrial waste water. Bull Mater. Sci., 25(6) (2002) 533-536

[4] Das S, Banthia A K, Adhikari B. Porous polyurethane urea membranes for pervaporation separation of phenol and chlorophenols from water. Chem. Eng. J. 138(1-3) (2008) 215-223 